\title{
Autonomic nervous system activity in purebred Arabian horses evaluated according to the low frequency and high frequency spectrum versus racing performance
}

\author{
Iwona Janczarek ${ }^{1}$, Witold Kędzierski², Anna Stachurska ${ }^{1}$, Izabela Wilk ${ }^{1}$, \\ Ryszard Kolstrung ${ }^{1}$, Katarzyna Strzelec ${ }^{1}$
}

\begin{abstract}
University of Life Sciences in Lublin, ${ }^{1}$ Faculty of Biology, Animal Sciences and Bioeconomy, Department of Horse Breeding and Use, ${ }^{2}$ Faculty of Veterinary Medicine,

Department of Biochemistry, Lublin, Poland
\end{abstract}

Received July 15, 2015

Accepted December 2, 2016

\begin{abstract}
Emotional excitability influences horses' performance in sports and races. The aim of the study was to analyse whether the balance of the autonomic system which can occur when sympathetic system activity is at various levels might impact the horses' racing performance. The study was carried out on 67 purebred Arabian horses trained for racing. The following indices were analysed: low frequency (LF), high frequency (HF), and the ratio of spectrum power at low frequencies to high frequencies $(\mathrm{LF} / \mathrm{HF})$. The autonomic nervous system activity was measured $\times 3$ during the training season, at three-month intervals. Each examination included a 30-min measurement at rest and after a training session. The racing performance indices in these horses were also analysed. Better racing results were found in horses with enhanced LF/HF. The worst racing results were determined in horses with low LF.
\end{abstract}

Racehorses, heart rate variability, ANS

The autonomic nervous system is characterised by an irregular distribution of centres, relatively slow conduction of nervous impulses, smooth muscles acting as effectors, and cardiac-type striated tissue and glands (Low 1993). There are numerous autonomic nervous system functions; heart rate acceleration or deceleration being one of them. The autonomic system is divided into the sympathetic system (stimulating) and the parasympathetic system (inhibiting) (Verrier and Lown 1978). All the internal organs are innerved simultaneously by both of these systems. The sympathetic and parasympathetic system activities are antagonistic to each other. In stressful situations, the sympathetic system activity dominates the effects of the parasympathetic component (Baselli et al. 1987, Gill 2003). An increase in the sympathetic component, together with the secretion of epinephrine and norepinephrine, accelerates the heart rate, whereas an increased tone of the parasympathetic system (acetylocholine secretion) decreases the heart rate (Dempsey and Cooper 1969).

The activity and balance of the autonomic system can be analysed by measuring the variability of the sinus rhythm (heart rate variability, HRV). This variability is a cyclic occurrence of differences in R-R intervals (the time between complexes of QRS waves in electrocardiogram). The R-R depends on the effects of the mechanisms controlling the activity of the sinoatrial node (Kautzner 1995; von Borell et al. 2007). The rhythm variability can be investigated with a number of methods, including a time method and a frequency (spectral) method (Noszczyk-Nowak and Bogucki 2013; Wilk and Janczarek 2015). The spectral method allows to precisely determine whether the autonomic system balance results simply from low activity of the sympathetic system or from high activity of the sympathetic component accompanied by high activity of the parasympathetic system. A lack of balance in the autonomic system unambiguously

Address for correspondence:

Iwona Janczarek

Department of Horse Breeding and Use

University of Life Sciences in Lublin

Akademicka 13, 20-950 Lublin, Poland
Phone: +48814456503

Fax: +48814456973

E-mail: iwona.janczarek@up.lublin.pl

http://actavet.vfu.cz/ 
indicates that the sympathetic component predominates over the parasympathetic part. It has been proven that the emotional status of a horse has a large impact on racing results (Hada et al. 2003). An intermediate level of emotional excitability is assumed to be the most beneficial for racing horses (Calabrese 2008).

In this paper, the hypothesis was put forward that the balance of the autonomic system which can occur when sympathetic system activity is of various level, might impact the racing performance indices. It was assumed that both high sympathetic system activity accompanied by high parasympathetic activity, and high sympathetic system activity that is not counterbalanced by the parasympathetic component, may negatively influence the racing outcomes as these activities reflect the stress response in the body.

The objective of the paper was to analyse the racing performance indices in horses assigned to different groups according to the different degrees of autonomic nervous system balance.

\begin{abstract}
Materials and Methods
Horses

The study involved 67 clinically healthy purebred Arabian horses that had undergone racing training for two consecutive years on the racing track "Tor Służewiec" in Warsaw, Poland. At the beginning of the experiment, the age of the horses ranged between 32 and 36 months. At that point, the horses were being routinely trained for racing and had taken part in races during their first racing season. Before the experiment, the horses had been kept in two racing stables within the same racing track facilities. Over the course of this 6-month long experiment, the horses continued to be trained and take part in races. The training sessions schedule was arranged according to a uniform system. Individual training loads were adjusted to the needs of each horse. Training sessions were held in the mornings. In the pre-racing period, the horses were in training for six consecutive days; the seventh day was a resting day. The horses were kept in a stable or walked on a horsewalker on the resting day. A standard training session lasted approximately $30 \mathrm{~min}$. After the session, the unsaddled horses were walked on a horsewalker for additional $30 \mathrm{~min}$ and then brought back to their boxes. During the racing season, stallions did not race more often than once in 10 days. Mares raced up to a maximum of 10 competitions per season. In the racing period, walking on a horsewalker was arranged on the day preceding a race and for two days after a competition. In each stable, horses were fed $\times 3$ per day. Basic coat and hoof care procedures were performed after the morning feeding. The lights-out period lasted from 20:00 h till 6:00 h. The feeding system was consistent with the racing standards and was comparable for all the horses.
\end{abstract}

\title{
Heart rate variability (HRV) measurements
}

The experiment included an assessment of the emotional status of the horses based on the autonomic nervous system activity. This activity was determined using the spectraol (frequency) method (von Borell et al. 2007). The following indices were analysed:

1. Low frequency (LF): this refers to spectrum power at low frequencies $(0.04-0.15 \mathrm{~Hz})$. It indicates a sympathetic system response as a direct reflection of the emotional response, $\left(\mathrm{ms}^{2}\right)$.

2. High frequency (HF): This refers to spectrum power at high frequencies $(0.16-0.4 \mathrm{~Hz})$. These indices are expressed in $\mathrm{ms}^{2}$. High frequency spectrum is a response of the parasympathetic system, $\left(\mathrm{ms}^{2}\right)$.

3. LF/HF: this refers to the ratio of spectrum power at low frequencies to high frequencies expressed as \% values. Balancing of the autonomic nervous system is indicated by LF/HF (Kozek et al. 2006).

Evaluation of the autonomic nervous system activity was performed $\times 3$ : at the beginning of the training sessions (the $1^{\text {st }}$ examination), after three months of training (the $2^{\text {nd }}$ examination), and after six months of training (the $3^{\text {rd }}$ examination). Measurements of the selected HRV indices were taken twice during each examination. The first measurement was taken at rest in the mornings (the resting measurement) and the second one right after walking on a horsewalker (post-exercise measurement). All measurements were taken in the individual horse boxes. Each measurement lasted $30 \mathrm{~min}$.

The measurements were taken with RS800CX telemetric heart rate meters (POLAR) which consisted of an electrode with a built-in Polar WearLink ${ }^{\circledR}$ (W.I.N.D) transmitter and a receiver. Analyses of the HRV indices were done using Kubios HRV software, version 2.0 (Biomedical Signal Analysis Group, Department of Applied Physics, University of Kuopio, Finland 2008). To remove the trend components, the data were detrended, and the artefact correction was done following established procedures (Tarvainen 2002).

Evaluation of the emotional status: the procedure

The collected data on LF, HF, and LF/HF were divided into two ranges: low values (smaller than the mean) and high values (higher than the mean). The percentage proportion of horses in each range was then calculated. Thus, horses with low and high activity of the autonomic system components were divided. Consequently, it 
was possible to identify horses with a balanced autonomic system. The next step involved an analysis of the LF indicator that was within the low range of LF/HF values. The objective was to obtain information on: whether a high balance of the autonomic system (i.e. low LF/HF) is caused by low activity of the sympathetic system, which is also reflected by low activity of the parasympathetic system, or whether high activity of the sympathetic system is accompanied by high activity of the parasympathetic system. The Low Frequency indicator that was within the low LF/HF range was sorted and divided by the means. "Below the mean" meant a low range that was also called "a low, less active LF/HF". "Above the mean" meant a high range called "a low active LF/HF" range. The percentage of horses for each of these ranges was again calculated.

Racing performance indicators

The indicators of racing performance in the examined horses were also analysed and assigned to three ranges: high $\mathrm{LF} / \mathrm{HF}$ values, low LF/HF values that were accompanied by low LF values (a low, less active range), and low LF/HF values that were accompanied by high LF values (a low, active range). The following measures were included: the prize money won (PLN) (the prize money won by a horse in all races in which it participated during the racing season); a success coefficient (a quotient of prize money won by each horse to the average sum of money earned by peers); the general handicap $(\mathrm{GH})$ (a theoretical weight that a horse could carry in a race to equal its chances in relation to its peers, www.pkwk.pl 2014).

\section{Statistical methods}

The mean values of indices recorded at rest and after exercise and indices of racing performance were compared using the multivariate analysis of variance (ANOVA GLM). The analysis included the following factors: the horse's sex, the year of training, and the training facility. A comparison of the results from the consecutive repetitions was performed using analysis of variance for repeated measurements (SAS Institute Inc. 2003). Significance of differences between means was determined with Tukey's $t$-test. Significance of differences between the results expressed as percentage values was determined with Parker's test (Parker 1978).

\section{Results}

For those indices recorded at rest, significant differences were found for $\mathrm{HF}$ (Table 1). In the first examination, HF was significantly higher than the value recorded in the two other examinations. More differences were found between the means during postexercise measurements. It was found that LF and LF/HF were significantly lower in the first examination than in the other examinations. With each examination, HF decreased. Significant differences were found between the results of the first and third examination.

Table 1. HRV indices at rest and post-exercise.

\begin{tabular}{|c|c|c|c|c|c|c|c|c|c|}
\hline \multirow[t]{2}{*}{ Examination } & \multicolumn{3}{|c|}{$1^{\mathrm{st}}$} & \multicolumn{3}{|c|}{$2^{\text {nd }}$} & \multicolumn{3}{|c|}{$3^{\text {rd }}$} \\
\hline & $\mathrm{LF}^{*}$ & $\mathrm{HF}$ & $\mathrm{LF} / \mathrm{HF}$ & LF & $\mathrm{HF}$ & $\mathrm{LF} / \mathrm{HF}$ & LF & $\mathrm{HF}$ & $\mathrm{LF} / \mathrm{HF}$ \\
\hline \multicolumn{10}{|c|}{ Resting measurement } \\
\hline \multirow[t]{2}{*}{ Mean } & 843.32 & 472.26 & 178.65 & 878.39 & 384.21 & 228.58 & 1051.28 & 374.65 & 280.62 \\
\hline & ax & ax & ax & ax & bx & ax & ax & bx & ax \\
\hline $\mathrm{SD}$ & 301.12 & 109.56 & 102.22 & 311.87 & 119.35 & 99.78 & 523.23 & 107.37 & 102.33 \\
\hline \multicolumn{10}{|c|}{ Post-exercise measurement } \\
\hline$\overline{\text { Mean }}$ & 1057.34 & 502.17 & 210.57 & 1427.45 & 411.66 & 458.11 & 1479.98 & 366.56 & 403.81 \\
\hline & ax & $\mathrm{ax}$ & ay & by & $\mathrm{acx}$ & by & by & bcx & by \\
\hline SD & 548.45 & 108.36 & 113.62 & 463.28 & 108.73 & 152.56 & 702.22 & 129.61 & 107.62 \\
\hline
\end{tabular}

The means denoted with different letters differ significantly at $P \leq 0.05$ : a,b,c - comparison in rows, $\mathrm{x}, \mathrm{y}-$ comparison in columns.

*Heart rate variability (HRV)

LF - low frequency $\left(\mathrm{ms}^{2}\right)$;

$\mathrm{HF}$ - high frequency $\left(\mathrm{ms}^{2}\right)$;

$\mathrm{LF} / \mathrm{HF}$ - ratio of spectrum power at low frequencies to high frequencies $(\%)$.

Significant differences between the at-rest and post-exercise indices were recorded for $\mathrm{LF} / \mathrm{HF}$ in all the examinations, and LF in the second and third examination. In each of these cases, the indices at rest were lower than those determined after physical exercise. 
During the first examination at rest, twice as many horses with LF within the low range were identified in comparison with horses within the range of high values (Table 2). In the second examination, a proportion of LF in both value ranges was comparable. In the third examination, a high range of LF values was measured in $60 \%$ of the horses. The opposite of what was recorded for LF, was found for $\mathrm{HF}$ and $\mathrm{LF} / \mathrm{HF}$.

Table 2. Percentage of horses assigned to the low and high range of HRV indicator values.

\begin{tabular}{|c|c|c|c|c|c|c|}
\hline \multirow{2}{*}{$\begin{array}{l}\text { Examination } \\
\text { Range of values }\end{array}$} & \multicolumn{2}{|c|}{$1^{\text {st }}$} & \multicolumn{2}{|c|}{$2^{\text {nd }}$} & \multicolumn{2}{|c|}{$3^{\text {rd }}$} \\
\hline & Low & High & Low & High & Low & High \\
\hline \multicolumn{7}{|c|}{ Resting measurement } \\
\hline$\overline{\mathrm{LF}^{*}}$ & $67 a x$ & $33 a x$ & $52 \mathrm{ax}$ & $48 \mathrm{ax}$ & $40 \mathrm{bx}$ & $60 \mathrm{bx}$ \\
\hline $\mathrm{HF}$ & $34 \mathrm{ax}$ & $66 a x$ & $57 b x$ & $43 b x$ & $70 \mathrm{bx}$ & 30bx \\
\hline $\mathrm{LF} / \mathrm{HF}$ & $69 \mathrm{ax}$ & $31 \mathrm{ax}$ & $45 b x$ & $55 b x$ & $32 b x$ & $68 \mathrm{bx}$ \\
\hline \multicolumn{7}{|c|}{ Post-exercise measurement } \\
\hline$\overline{\mathrm{LF}}$ & 33ay & 67ay & $52 b x$ & $48 b x$ & 67by & 33by \\
\hline $\mathrm{HF}$ & 62ay & 38ay & $47 a x$ & $53 b x$ & $61 \mathrm{ax}$ & $39 a x$ \\
\hline LF/HF & $57 \mathrm{ax}$ & $43 a x$ & $54 \mathrm{ax}$ & $46 a x$ & 64ay & 46ay \\
\hline
\end{tabular}

The means denoted with different letters differ significantly at $P \leq 0.05$ : a,b,c - comparison in rows, $\mathrm{x}, \mathrm{y}-$ comparison in columns.

* Heart rate variability (HRV)

LF - low frequency $\left(\mathrm{ms}^{2}\right)$;

$\mathrm{HF}$ - high frequency $\left(\mathrm{ms}^{2}\right)$;

$\mathrm{LF} / \mathrm{HF}$ - ratio of spectrum power at low frequencies to high frequencies (\%).

The patterns of indices were different in the first and third post-exercise examinations. In the first examination, a majority of horses had LF in the high range of values and HF in the low range. In the third examination, both LF and HF were within the high value range in most horses. During two subsequent post-exercise examinations, the percentage proportion of horses with low LF/HF was similar to that recorded in the high range of values. In the third examination, the proportion of horses with LF/HF within the high range was smaller by $34 \%$ than the proportion of horses in the low range. Significant differences between the results at rest and post-exercise included LF and $\mathrm{HF}$ in both ranges in the first examination, and $\mathrm{LF}$ and $\mathrm{LF} / \mathrm{HF}$ in the third examination.

Table 3. The recorded LF and HF indices at rest and post-exercise within the low range of LF/HF values.

\begin{tabular}{|c|c|c|c|c|c|c|}
\hline \multirow[t]{2}{*}{ Examination } & \multicolumn{2}{|c|}{$1^{\mathrm{st}}$} & \multicolumn{2}{|c|}{$2^{\text {nd }}$} & \multicolumn{2}{|c|}{$3^{\text {rd }}$} \\
\hline & $\mathrm{LF}^{*}$ & $\mathrm{HF}$ & LF & $\mathrm{HF}$ & LF & $\mathrm{HF}$ \\
\hline \multicolumn{7}{|c|}{ Resting measurement } \\
\hline Mean & $902.16 a x$ & $511.45 \mathrm{ax}$ & $935.34 \mathrm{ax}$ & 463.61acx & $922.45 \mathrm{ax}$ & $428.65 b c x$ \\
\hline SD & 413.32 & 127.59 & 435.34 & 131.34 & 411.34 & 102.04 \\
\hline \multicolumn{7}{|c|}{ Post-exercise measurement } \\
\hline Mean & 1012.32ax & 598.57ax & $1113.37 \mathrm{ax}$ & $449.04 \mathrm{bx}$ & 1204.23ay & $471.45 b x$ \\
\hline SD & 428.61 & 202.34 & 567.43 & 134.54 & 464.63 & 169.54 \\
\hline
\end{tabular}

The means denoted with different letters differ significantly at $P \leq 0.05$ : a,b,c - comparison in rows, $\mathrm{x}, \mathrm{y}-$ comparison in columns.

*Heart rate variability (HRV)

LF - low frequency $\left(\mathrm{ms}^{2}\right)$;

$\mathrm{HF}$ - high frequency $\left(\mathrm{ms}^{2}\right)$;

$\mathrm{LF} / \mathrm{HF}$ - ratio of spectrum power at low frequencies to high frequencies (\%). 
Low frequency (LF) at rest and post-exercise, within the low range of the LF/HF values, did not differ significantly in the consecutive examinations (Table 3). However, in the third examination, HF was significantly lower than the value recorded in the first examination. Significant differences between the values at rest and post-exercise were also recorded for LF in the third examination.

Table 4. Percentage of horses in the low and high LF range recorded in the low $\mathrm{LF} / \mathrm{HF}$ value range.

\begin{tabular}{|c|c|c|c|c|c|c|}
\hline \multirow{2}{*}{$\begin{array}{l}\text { Examination } \\
\text { Range of values }\end{array}$} & \multicolumn{2}{|c|}{$1^{\text {st }}$} & \multicolumn{2}{|c|}{$2^{\text {nd }}$} & \multicolumn{2}{|c|}{$3^{\text {rd }}$} \\
\hline & Low & High & Low & High & Low & High \\
\hline \multicolumn{7}{|c|}{ Resting measurement } \\
\hline$\%$ & $\begin{array}{l}68 \\
\text { ax }\end{array}$ & $\begin{array}{l}32 \\
\mathrm{ax}\end{array}$ & $\begin{array}{l}48 \\
b x\end{array}$ & $\begin{array}{l}52 \\
b x\end{array}$ & $\begin{array}{l}39 \\
b x\end{array}$ & $\begin{array}{l}61 \\
b x\end{array}$ \\
\hline \multicolumn{7}{|c|}{ Post-exercise measurement } \\
\hline$\%$ & $\begin{array}{l}43 \\
\text { ay }\end{array}$ & $\begin{array}{l}57 \\
\text { ay }\end{array}$ & $\begin{array}{l}42 \\
\mathrm{ax}\end{array}$ & $\begin{array}{l}58 \\
\text { ax }\end{array}$ & $\begin{array}{l}39 \\
\mathrm{ax}\end{array}$ & $\begin{array}{l}61 \\
\text { ax }\end{array}$ \\
\hline
\end{tabular}

The means denoted with different letters differ significantly at $P \leq 0.05$ : $\mathrm{a}, \mathrm{b}, \mathrm{c}$ - comparison in rows, $\mathrm{x}, \mathrm{y}$ - comparison in columns.

During the first examination at rest, a majority horses had LF within the low value range (Table 4). In the second examination, the proportion of horses in both ranges was comparable. In the third examination, LF in over $60 \%$ of horses was within the high value range. During the second and third post-exercise examination, the percentage proportion of horses in low and high LF ranges was comparable to the examinations at rest. In the first post-exercise examination, LF in low value ranges was slightly lower.

The total prize money won was significantly smaller in the group with low, less active $\mathrm{LF} / \mathrm{HF}$ range in relation to the other two LF/HF ranges (Table 5). The success coefficient differed significantly in each LF/HF range. The lowest value was recorded in the low, less active range and the highest was in the high range. A general handicap in the high range did not differ significantly from the other two ranges - where a measure in the low, active range was significantly higher than the one recorded in the low, less active range.

Table 5. Indices of racing performance in the horses assigned to the following LF/HF range: high, low active, and low inactive.

\begin{tabular}{|c|c|c|c|}
\hline Racing & Prize & Success & General \\
\hline performance & money won & coefficient & handicap \\
\hline \multicolumn{4}{|c|}{ High LF/HF* range } \\
\hline Mean & $9547.34 \mathrm{a}$ & $0.89 \mathrm{a}$ & $59.74 a$ \\
\hline SD & 1087.46 & 0.09 & 8.12 \\
\hline \multicolumn{4}{|c|}{ Low active LF/HF range } \\
\hline$\overline{\text { Mean }}$ & $12549.65 \mathrm{a}$ & $1.53 \mathrm{~b}$ & $66.23 \mathrm{ab}$ \\
\hline$\underline{\mathrm{SD}}$ & 4048.25 & 0.43 & 10.53 \\
\hline \multicolumn{4}{|c|}{ Low, less active LF/HF range } \\
\hline Mean & $4179.96 b$ & $0.51 \mathrm{c}$ & $52.67 \mathrm{ac}$ \\
\hline SD & 1022.45 & 0.06 & 7.17 \\
\hline
\end{tabular}

The means denoted with different letters differ significantly at $P \leq 0.05$.

$* \mathrm{LF} / \mathrm{HF}$ - ratio of spectrum power at low frequencies to high frequencies $(\%)$

It was also found that post-exercise LF and LF/HF values significantly increased after three months of the season whereas the HF value started to decrease in that period.
The results of this study indicate that differences in the autonomic nervous system activity in the examined horses are even found at rest. Three months into the racing season, the parasympathetic system activity decreased significantly and remained at a comparable level until the end of the season. However, other indices, namely LF (reflecting the sympathetic system activity) and LF/HF system balance) increased only slightly. (indicating the autonomic 
A significantly lower level of the HF value was reached at the end of the season rather than at the beginning of the season. It may be suggested that in horses that participate in races, stress responses increase progressively up to a point at which the body becomes unable to manage them. As reported by Kato et al. (2003), enhanced parasympathetic system activity reflects a state of physical and mental relaxation. It exerts a trophotropic effect on the regeneration processes by inhibiting utlization of matter and energy (Baselli et al. 1987; Gill 2003). The results of this study, however, indicate the complete opposite, emphasised by the negative impact of race training on the emotional status of horses, as described by Landers (2006).

Interesting results were also recorded while comparing the parameters at rest with the ones measured after physical exercise. There is an increase in the activity of the sympathetic system, although the parasympathetic system remains at an approximate level. Obviously, such pattern of the autonomic system components contributes to a disruption of the balance of this system. It has been proven that an increase in the activity of the sympathetic system is caused both by physical exercise (Voss 2002) and a need for enhanced alertness, for instance, when horses are introduced to new facilities (Wilk et al. 2015). It is assumed that alertness increases as soon as the horse leaves the stable. Thus, stress in horses caused by being in a racing facility is potentiated by numerous factors. Cooper and Albentosa (2005) are of a similar opinion in their descriptions of the hazards threatening the welfare of horses associated with the racing industry.

The percentage of horses assigned to the range of low and high values of the examined indices is another issue. At the beginning of the racing season, most horses have a low, resting sympathetic system activity and a high autonomic nervous system balance but the situation is the opposite at the end of the season. The proportion of horses in the range of low and high values found in our study shows that the parasympathetic system activity follows a reverse pattern. Throughout subsequent months of the racing season, the number of horses with high HF decreases. However, during the examinations carried out after physical exercise, the pattern is opposite to the at-rest examinations. At the beginning of the season, most horses demonstrate sympathetic system activity categorised as high, as hypothesised by this paper. Most often the parasympathetic system activity is low. At the end of the season, the majority of horses were classified in the range of low LF and HF values. The results recorded after three months were similar to the results measured during the at-rest examinations. The number of horses with both low and high autonomic system balance was comparable for all examinations. It becomes clear how the activity associated with physical exercise and the restitution processes directly following exercise change throughout the racing season, and that the at-rest examination itself cannot be an unambiguous indicator of the emotional status in Purebred Arabian racing horses. Kinnunen et al. (2006) discuss changes in the autonomic nervous system activity caused not only by physical exercise but also by different phases of the training cycle. These authors reported an increased stress response in trotters after the racing season had started than in the preparation period. Moreover, increased activity of the autonomic nervous system was observed during highintensity training sessions that preceded participation in a race.

Interesting results were also recorded during the LF and HF analysis in the low range of $\mathrm{LF} / \mathrm{HF}$ values. Both the sympathetic and parasympathetic systems remained on a comparable activity level throughout the season. The activity of the indexes examined at rest and post-exercise were most often similar. It should be emphasised that a low LF/ HF level was most often associated with low autonomic nervous system activity at the beginning of the season yet with high activity at the end of the season. After physical exercise, the number of horses with both low and high LF was comparable at the beginning as well as three months into the racing season. The advantage of horses with high LF values became prominent only at the end of the season. 
In summary, it may be said that the balance of the autonomic nervous system at rest is most often achieved at the beginning of the racing season by low activity of the sympathetic system, which may indicate a low stress level in horses. At the end of the season, the activity of the parasympathetic system is enhanced, which, according to Rietmann et al. (2004), eliminates stress both at rest and post-exercise.

It was also found that the racing performance indexes in the horses assigned to different activity ranges of the autonomic system most often were different. In the group of horses categorised into the low, active LF/HF range (characterised by enhanced activity of the sympathetic system accompanied by an increased activity of the parasympathetic system), a higher level of racing performance indices may be expected in comparison with the other groups of horses. The group of horses with a high LF/HF range (with increased activity of the sympathetic system) is second in terms of beneficial values of racing performance indicators. The lowest results should be expected in horses with low sympathetic system activity. The results of this study confirm the opinion expressed by McBride and Millis (2012) that a mental characteristic described as "flightness" may be associated with susceptibility to stress. Flightness positively impacts racing results in horses, although it is not desired, for instance, in dressage horses. In racing horses, this characteristic is most probably associated with a high susceptibility to stress which does not go hand-in-hand with bravery. A similar situation can be expected with excessive susceptibility of horses to stress (Hada et al. 2003). It may be suggested that the best racing horses are potentially those whose body is able to eliminate stress by means of enhanced parasympathetic system activity. Better results may also be expected in horses that are susceptible to stress than in horses that are resistant to it.

In conclusion, the activity of the autonomic nervous system at rest and post-exercise in purebred Arabian racing horses is varied and changes throughout the racing season. Both after physical exercise and in subsequent months of the training season, the activity of the sympathetic system is usually enhanced with a steady activity of the parasympathetic system. The parasympathetic system activity decreases over the subsequent months of the racing season. Better racing results may be expected in horses with enhanced sympathetic system activity accompanied by an increased activity of the parasympathetic system than in horses with high sympathetic system activity but low activity of the parasympathetic system. The lowest racing performance may be characteristic for horses with low sympathetic system activity.

\section{Acknowledgements}

The study was supported by the National Centre for Research and Development, Poland (grant N180061).

\section{References}

Baselli G, Cerutti S, Civardi S, Lombardi F, Malliani A, Merri M, Rizzo G 1987: Heart rate variability signal processing: a quantitative approach as an aid to diagnosis in cardiovascular pathologies. Int J Biomedi Comp 20: $51-70$

Calabrese EJ 2008: Converging concepts: adaptive response, preconditioning, and the Yerkes-Dodson Law are manifestations of hormesis. Ageing Research Reviews: 7: 8-20

Cooper JJ, Albentosa MJ 2005: Equine behaviour and welfare. In: Mills D, McDonnel S (Eds): The Domestic Horse: The Evolution, Development and Management of Its Behavior. Cambridge University Press, Cambridge UK: pp 228-238

Dempsey PJ, CooperT 1969: Ventricular cholinergic receptor systems: interaction with adrenergic systems. Journal of Pharmacology and Experimental Therapeutics 167: 282-290

Gill J 2003: Fizjologia konia (Physiology of the horse, in Polish). Sport Press Warsaw

Hada T, Onaka T, Takahashi T, Hiraga A, Yagi K 2003: Effects of novelty stress on neuroendocrine activities and running performance in thoroughbred horses. J Neuroendocrinol 15: 638-648

Kato T, Ohmura H, Hiraga A, Wada S, Kuwahara M, Tsubone H 2003: Changes in heart rate variability in horses during immersion in warm springwater. American J Vet Res 64: 1482-1485 
Kautzner J 1995: Reproducibility of heart rate variability measurements. In: Malik M, Camm AJ (Eds): Heart Rate Variability. Armonk, N.Y., Futura Publ. Comp, Inc, pp 165-171

Kinnunen S, Laukkanen R, Haldi J, Hanninen O, Atalay M 2006: Heart rate variability in trotters during different training periods. Equine Vet J 38: 214-217

Kozek E, Witek P, Małecki M, Foltyn A, Borodako A, Sieradzki J 2006: Zależność wskaźników analizy czasowej i częstotliwościowej dobowej zmienności rytmu serca, odstępu i dyspersji QT oraz JT i ich wartości skorygowanych u chorych na cukrzycę typu 1 (Relation of indices of time and frequency 24-hour heart rate variability, interval and dispersion of QT and JT and their corrected values in type 1 diabetes, in Polish). Diabetologia Praktyczna 6: 382-389

Landers TA 2006 Professional Care of the Racehorse: A Guide to Grooming, Feeding, and Handling the Equine Athlete. Eclipse Press, Lexington, KY

Low PA 1993: Autonomic nervous system function. J Clin Neurophysiol 10: 14-27

McBride SD, Mills DS 2012: Psychological factors affecting equine performance. BMC Vet Res 8: 180

Noszczyk-Nowak A, Bogucki SZ 2015: Zmienność rytmu serca (HRV) jako nowe narzędzie diagnostyczne w medycynie weterynaryjnej (Heart rate variability (HRV) as a new diagnostic tool in veterinary medicine, in Polish). Weterynaria w praktyce 6: 46-50

Parker RE 1978: Wprowadzenie do statystyki dla biologów (Introduction to statistics for biologists, in Polish). PWN Warszawa, $133 \mathrm{p}$.

Rietmann TR, Stuart AEA, Bernasconi P, Stauffacher M, Auer JA, Weishaupt MA 2004: Assessment of mental stress in warmblood horses: heart rate variability in comparison to heart rate and selected behavioral parameters. Appl Anim Behav Sci 88: 121-136

SAS Institute Inc. CNU SAS user's guide statistics: version 9.1.3. Cary NC: 2003

Tarvainen MP, Ranta-Aho PO, Karjalainen PA 2002: An advanced detrending method with application to HRV analysis. IEEE T Biomed Engd 49: 172-175

Verrier RL, Lown B1978: Sympathetic-parasympathetic interactions and ventricular electrical stability. In: Vaughan Williams EM (Ed.): Neural Mechanisms in Cardiac Arrhythmias. Raven Press New York, pp. 75-85

von Borell E, Langbein J, Després G, Hansen S, Leterrier C, Marchant-Forde J, Veissier I 2007: Heart rate variability as a measure of autonomic regulation of cardiac activity for assessing stress and welfare in farm animals - a review. Physiol Behav 92: 293-316

Voss B, Mohr E, Krzywanek H 2002: Effects of aqua-treadmill exercise on selected blood parameters and on heart-rate variability of horses. J Vet Med Series A 49: 137-143

Wilk I, Janczarek I 2015: Relationship between behavior and cardiac response to round pen training. J Vet Behav 10: $231-236$

Wilk I, Kędzierski W, Stachurska A, Janczarek I 2015: Are results of Crib Opening Test connected with efficacy of training horses in a round-pen? Appl Anim Behav Sci 166: 89-97

www.pkwk.pl: 2014 - Polish Jockey Club official website (accessed Dec 1, 2014) 